Mathematics and Educations Journal

Volume 1 Nomor 1, Juni 2019

\title{
PENGEMBANGAN MEDIA PEMBELAJARAN MATEMATIKA BERBASIS GAME: STATISTICS IN ARCTIC
}

\author{
Nilza Humaira Salsabila ${ }^{1}$, Wahyu Setyaningrum ${ }^{2}$ \\ ${ }^{1}$ Program Studi Pendidikan Matematika, FKIP, Universitas Mataram, \\ nilza_hs@unram.ac.id \\ ${ }^{2}$ Program Pascasarjana Pendidikan Matematika, Universitas Negeri Yogyakarta, \\ wahyu_setyaningrum@uny.ac.id
}

\begin{abstract}
Abstrak. Tujuan dari penelitian ini adalah untuk mengembangkan media pembelajaran matematika yang berbasis Game untuk siswa kelas VIII SMP. Media pembelajaran yang dikembangkan merupakan game smartphone pada materi statistika yang berjudul STATIC (Statistics in Arctic). Pengembangan Game STATIC dilakukan berdasarkan pada model ADDIE (Analyze-Design-Develop-Implement-Evaluate) dengan lima tahapan utama, yaitu analisis, perancangan, pengembangan, implementasi, dan evaluasi. Game STATIC yang dikembangkan harus memenuhi kriteria valid. Kevalidan dari media yang dikembangkan berdasarkan pada penilaian para ahli media. Instrumen untuk menilai kevalidan berupa lembar validasi media pembelajaran oleh ahli media. Hasil penilaian ahli media menunjukkan skor rata-rata sebesar 152 dengan klasifikasi sangat baik. Dapat disimpulkan bahwa media Game STATIC memenuhi kriteria valid dan layak untuk digunakan dalam pembelajaran matematika.
\end{abstract}

Kata Kunci: Media Pembelajaran, Matematika, Game

\section{DEVELOPING GAME-BASED MATHEMATICS INSTRUCTIONAL MEDIA: STATISTICS IN ARCTIC}

\begin{abstract}
The purpose of this study is to develop a game-based mathematics instructional media for $8^{\text {th }}$ junior high school students. Instructional media developed is a smartphone game in statistics material that called STATIC (Statistics in the Arctic). STATIC Game Development is based on the ADDIE model with five main phases, analyze, design, develop, implement, and evaluate. The STATIC game developed must meet valid criteria. The validity of the media was developed based on the assessment of media experts. The instrument for assessing validity was instructional media validation sheet by media experts. The results of the media expert's assessment showed an average score 152 with very good classification. It can be concluded that the STATIC Game media meet valid criteria and good for use in mathematics learning.
\end{abstract}

Keywords: Instructional Media, Mathematics, Game 
Mathematics and Educations Journal

Volume 1 Nomor 1, Juni 2019

\section{PENDAHULUAN}

Teknologi merupakan hal yang sangat dekat dengan kehidupan masyarakat saat ini. Segala kebutuhan masyarakat dapat terpenuhi dengan cepat karena kemajuan teknologi. Perkembangan teknologi yang sangat pesat juga merupakan salah satu sarana untuk meningkatkan kualitas pembelajaran matematika. Pembelajaran yang efektif dapat diwujudkan dengan bantuan teknologi [1]. Siswa juga dapat belajar dengan cara yang modern melalui teknologi [2]. Maka, meningkatkan kualitas pembelajaran dengan mengintegrasikan teknologi merupakan hal yang penting untuk dilakukan.

Salah satu cara untuk meningkatkan kualitas pembelajaran matematika dengan memanfaatkan teknologi adalah mengembangkan media pembelajaran berbasis game edukasi. Game edukasi merupakan salah satu media yang dapat digunakan siswa untuk mempelajari matematika. Indonesia mempunyai potensiyang besar untuk menggunakan game sebagai media pembelajaran. Hasil survei Daily Social pada tahun 2016 [3] menunjukkan bahwa salah satu kegiatan yang paling sering dilakukan oleh anak usia 18 tahun ke bawah di smarthphone adalah bermain game, yaitu sebesar 64\% (lihat Gambar 1). Indonesia juga dikatakan sebagai negara dengan jumlah pengunduh terbanyak aplikasi game berbasis android [4].

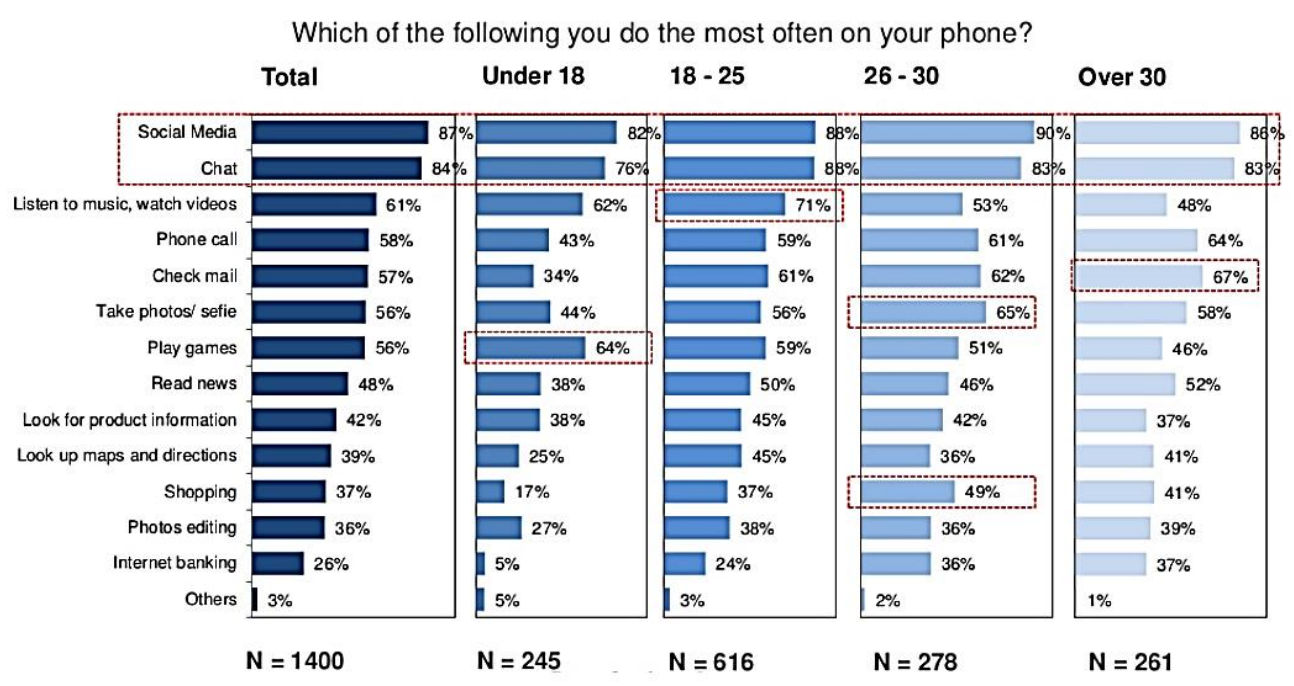

Gambar 1. Survei Daily Social Penggunaan Smartphone di Indonesia Tahun 2016 
Mathematics and Educations Journal

Volume 1 Nomor 1, Juni 2019

Game begitu populer di masyarakat karena membuat pengguna menikmati permainan dan termotivasi untuk terus memainkannya [5]. Media game edukasi di smartphone juga memiliki beberapa keuntungan, salah satunya dapat dimainkan kapanpun dan dimanapun. Melalui game edukasi siswa dapat bermain sekaligus belajar dengan cara yang menyenangkan.

Lebih lanjut, media game yang dikembangkan harus dapat meningkatkan aspek kognitif maupun afektif siswa, seperti pemahaman konsep dan minat belajar. Winarko [6] menyatakan bahwa media pembelajaran games dapat membantu siswa dalam memahami konsep matematika. Melalui menyelesaikan misi dalam game siswa dapat membangun konsep matematika [7]. Misi yang disajikan dalam game juga meningkatkan minat siswa untuk belajar matematika [8]. Penelitian yang dilakukan Putra dan Setyaningrum juga mengungkapkan bahwa game edukasi efektif untuk meningkatkan minat belajar siswa [9].

Model pembelajaran yang disajikan dalam game juga harus diperhatikan agar materi dapat tersampaikan dengan baik. Salah satu model pembelajaran yang dapat membantu siswa untuk memahami konsep dan menarik minat siswa adalah model Problem Based Learning. Model Problem Based Learning adalah suatu model pembelajaran yang menyajikan masalah yang dekat dengan kehidupan sehari-hari siswa [10]. Masalah yang disajikan dalam PBL dapat memfasilitasi siswa untuk menentukan konsep-konsep yang diperlukan [11]. Minat siswa juga dapat meningkat dengan menyelesaikan masalah yang dekat dengan kehidupan mereka.

Beberapa penelitian sebelumnya telah menunjukkan bahwa penggunaan media pembelajaran game dapat meningkatkan kualitas pembelajaran matematika. Kebritchi et al. [7] menemukan bahwa game edukasi menyajikan lingkungan yang akrab bagi siswa, sehingga siswa dapat membangun konsep matematika mereka. Kiili, Moeller, dan Ninaus [12] juga mengungkapkan hal serupa, bahwa penggunaan game dapat meningkatkan pengetahuan konsep siswa secara efektif. Lebih lanjut, Prince [13] dalam penelitiannya menunjukkan bahwa pembelajaran berbasis game dalam pengajaran mempengaruhi minat siswa pada materi Aljabar.

Namun, pemanfaatan media pembelajaran berbasis game di Indonesia masih terbatas. Guru masih kesulitan dalam mengunakan media pembelajaran berbentuk game 
Mathematics and Educations Journal

Volume 1 Nomor 1, Juni 2019

edukasi. Hal ini dikarenakan beberapa faktor antara lain, guru menganggap belajar melalui game akan membuat siswa sulit untuk memahami materi pelajaran dan guru merasa tidak cukup waktu untuk menyelesaikan materi jika menggunakan media game [14]. Kemudian, aplikasi pembelajaran yang tersedia di Play Store juga masih sederhana, hanya berupa kumpulan rumus matematika dan latihan soal-soal. Terbatasnya media teknologi yang ada, maka penting untuk dikembangkan game edukasi guna memfasilitasi pembelajaran matematika siswa saat ini.

\section{METODE PENELITIAN}

Penelitian ini adalah penelitian pengembangan yang bertujuan untuk menghasilkan produk berupa media pembelajaran matematika berbasis game. Adapun media game mencakup materi statistika untuk siswa Kelas VIII SMP. Pada penelitian ini model pengembangan yang digunakan adalah model pengembangan ADDIE yang terdiri dari lima langkah [15] yaitu, analisis (analyze), perancangan (design), pengembangan (develop), implementasi (implement), dan evaluasi (evaluate).

\section{A. Analisis (Analyze)}

Tahapan pertama ADDIE dilakukan beberapa hal, yaitu analisis kurikulum, analisis karakteristik siswa, dan analisis sumber daya yang dibutuhkan.

\section{B. Perancangan (Design)}

Pada saat perancangan,peneliti menentukan jenis game, merancang flowchart dan storyboard, menyusun materi, serta mengumpulkan bahan untuk mengembangkan game.

\section{Pengembangan (Develop)}

Media pembelajaran game mulai dibuat pada tahap ini sesuai dengan perancangan sebelumnya. Kemudia game dinilai kevalidannya oleh para ahli.

\section{Implementasi (Implement)}

Pada tahap ini dilakukan uji coba lapangan untuk memperoleh data guna mengetahui kualitas (kepraktisan dan keefektivan) dari game yang dikembangkan.

\section{E. Evaluasi (Evaluate)}

Tahap terakhir ADDIE, peneliti menilai kualitas media game dan proses pembelajaran dengan media. 
Salah satu kriteria yang harus dipenuhi oleh media pembelajaran yang dikembangkan adalah kriteria validity (kevalidan) [16]. Media yang dikembangkan dikatakan memenuhi kriteria kevalidan jika dapat mengukur apa yang seharusnya diukur sesuai dengan tujuan pembuatannya [17]. Kevalidan media dinilai oleh validator yaitu para ahli media.

Penilaian kevalidan media game dilakukan oleh para ahli media menggunakan instrumen Lembar Validasi Media Pembelajaran oleh Ahli Media. Penilaian di lembar validasi juga digunakan sebagai bahan acuan untuk memperbaiki kualitas media game. Lembar validasi media disusunberdasarkan LORI, The Learning Object Review Instrument [18]. Lembar tersebut terdiri dari 35 butir pernyataan dengan 9 indikator antara lain: kualitas konten ( 2 butir), tujuan pembelajaran (3 butir), prosedur dan umpan balik (4 butir), efisiensi (3 butir), desain interface (12 butir), interaktivitas (6 butir), aksesbilitas ( 2 butir), usabilitas ( 2 butir), dan kesesuaian standar (1 butir). Adapun skala yang digunakan pada lembar validasi adalah skala likert 5: (1) sangat baik; (2) baik; (3) cukup; (4) kurang; dan (5) sangat kurang. Skor maksimum yang dapat diperoleh sebesar 175 dan skor minimum 35, sehingga diperoleh Tabel 1. Klasifikasi Kualitas Kevalidan Media Pembelajaran oleh Ahli Media [19]. Apabila hasil penilaian berada pada klasifikasi minimal baik $(X>119)$, maka media tersebut dikatakan valid.

Tabel 1. Klasifikasi Kualitas Kevalidan Media Pembelajaran oleh Ahli Media

\begin{tabular}{cc}
\hline Indikator & Klasifikasi \\
\hline$X>147$ & Sangat Baik \\
$119<X \leq 147$ & Baik \\
$91<X \leq 119$ & Cukup \\
$63<X \leq 91$ & Kurang \\
$X \leq 63$ & Sangat Kurang \\
\hline
\end{tabular}

\section{HASIL DAN PEMBAHASAN}

Media pembelajaran matematika yang dikembangkan pada penelitian ini berupa game edukasi dan diberi namaSTATIC (Statistics in Arctic). Game dikembangkan dengan menggunakan aplikasi Construct 2 dan game dapat dioperasikan melalui smartphone maupun laptop. Materi yang disajikan pada Game STATIC adalah materi 
Mathematics and Educations Journal

Volume 1 Nomor 1, Juni 2019

statistika kelas VIII SMP. Adapun model pembelajaran yang digunakan untuk menyajikan materi pada game adalah model Problem Based Learning dengan 5 sintaks yaitu: (1) Penyajian Masalah; (2) Perencanaan Penyelidikan; (3) Pelaksanaan Penyelidikan; (4) Penyajian Hasil Penyelidikan; dan (5) Refleksi. Masalah yang disajikan pada game juga sesuai dengan karakteristik model PBL yaiut menggunakan masalah dunia nyata.

Pada Game STATIC siswa diberikan misi untuk menyelesaikan level. Misi dapat diselesaikan jika siswa dapat menjawab masalah yang diberikan pada tiap level. Game STATIC terdiri atas 4 level dengan 4 sub materi pada tiap level. Sub materi yang disajikan pada level Game STATIC adalah:

- Level 1: Menganalisis Data dari Distribusi Data yang Diketahui.

- Level 2: Menentukan Nilai Rata-rata (Mean) dari Suatu Data.

- Level 3: Menentukan Median dan Modus Suatu Data.

- Level 4: Menentukan Ukuran Penyebaran Data.

Adapun berikut adalah rincian dan tampilan dari Game STATIC yang dikembangkan. Saat permainan Game STATIC dimulai, akan muncul tampilan menu utama. Beberapa tombol yang terdapat pada menu utama adalah tombol start, tombol petunjuk, tombol materi, tombol model, tombol suara, dan tombol keluar (lihat Gambar 2).

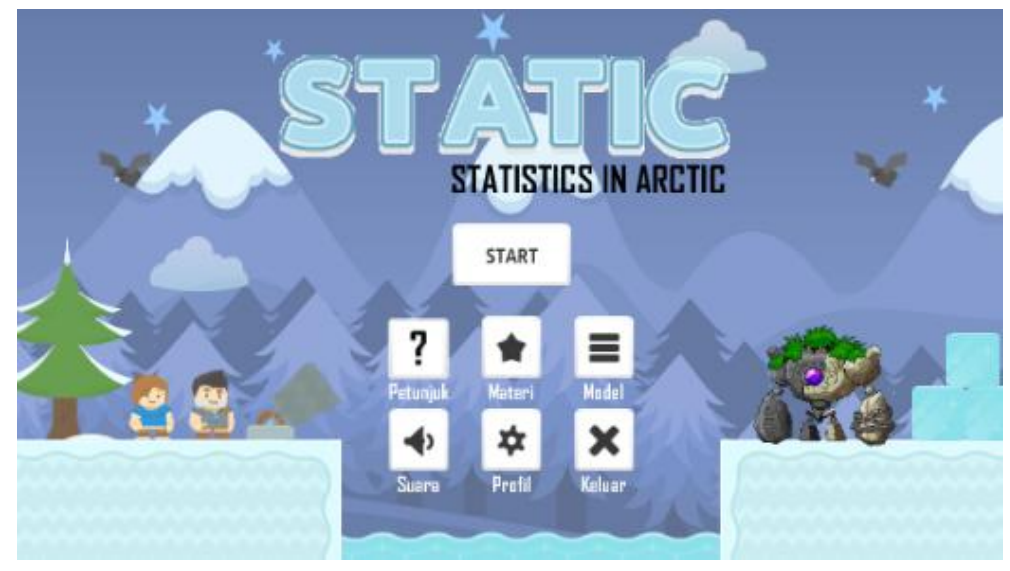

Gambar 2. Tampilan Menu Utama pada Game STATIC

Kemudian, tampilan stage pada Game STATIC mengambil latar pada wilayah kutub. Latar game pada wilayah kutub bertujuan menarik minat siswa untuk menyelesaikan level dan menuju level berikutnya.Selain itu, ilustrasi pada game 
Mathematics and Educations Journal

Volume 1 Nomor 1, Juni 2019

membuat siswa lebih tertarik untuk belajar dan memahami materi [20].Tiap level memiliki tampilan stage yang berbeda. Gambar 3. dan Gambar 4.merupakan contoh tampilan stage pada Game STATIC.

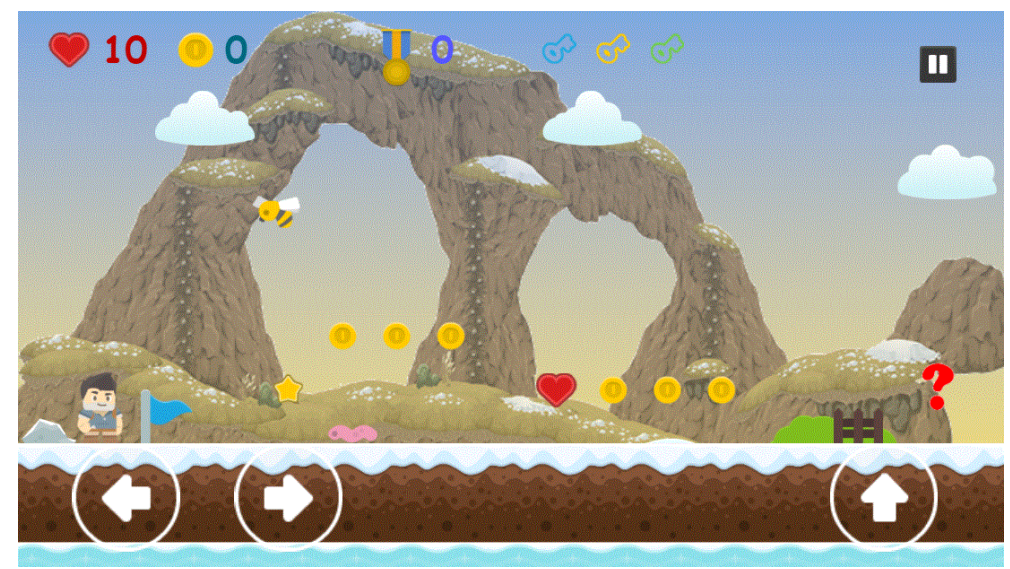

Gambar 3. Tampilan Salah Satu Stage pada Game STATIC bagian 1

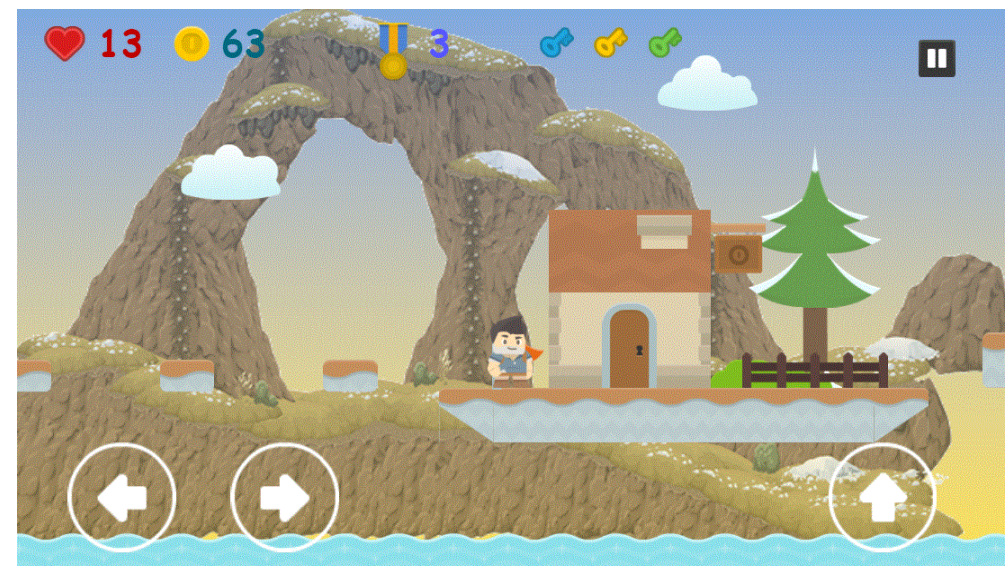

Gambar 4. Tampilan Salah Satu Stage pada Game STATIC bagian 2

Adapun tiap level pada Game STATIC memiliki misi yang berbeda untuk diselesaikan siswa. Misi pada game dapat meningkatkan pemahaman konsep dan minat belajar pada siswa [7]. Gambar 5. merupakan salah satu contoh petunjuk misi pada Game STATIC. 
Mathematics and Educations Journal

Volume 1 Nomor 1, Juni 2019

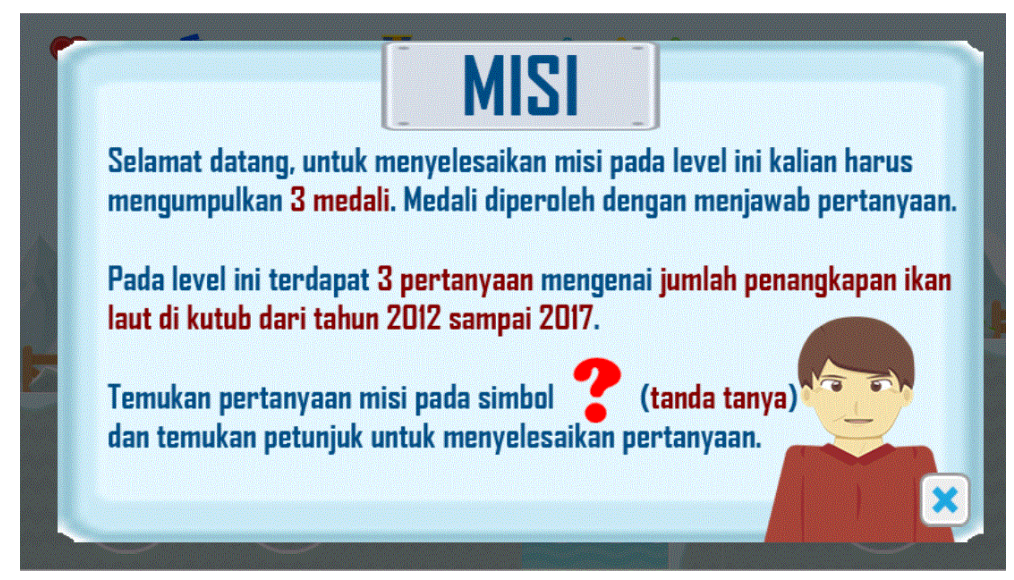

Gambar 5. Tampilan Petunjuk Misi pada Game STATIC

Pembelajaran materi statistika pada Game STATIC disajikan menggunakan model problem based learning yang menyajikan masalah dunia nyata. Melalui model PBL, pemahaman konsep matematika dan minat siswa juga dapat meningkat [21].

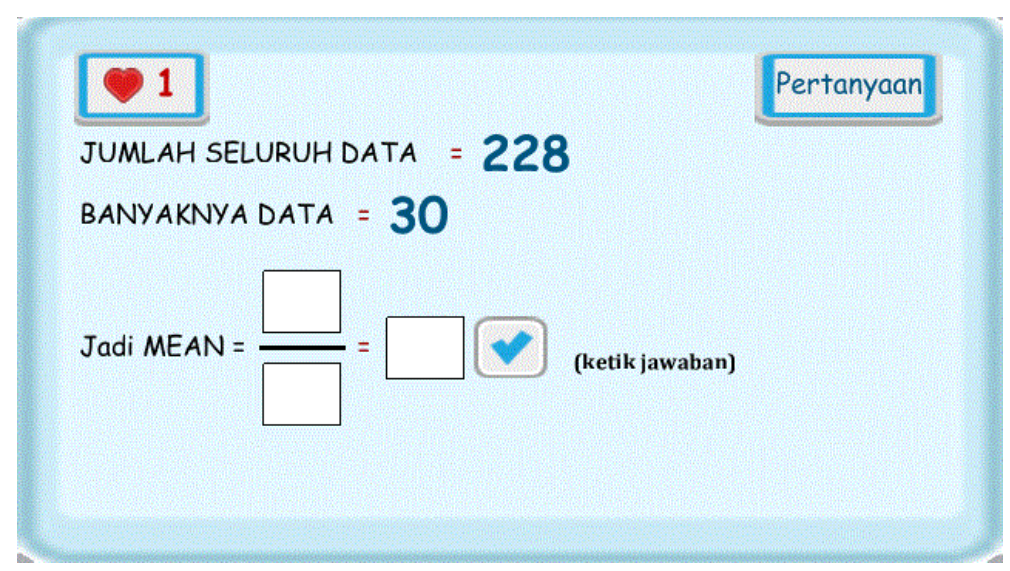

Gambar 6. Tampilan Materi pada Game STATIC

Tiap level pada game memiliki Boss Level yang harus dikalahkan oleh siswa. Siswa dapat mengalahkan Boss Level dengan menjawab benar 5 pertanyaan evaluasi yang diberikan. Berikut contoh tampilan dari Boss Level (lihat Gambar 7). 


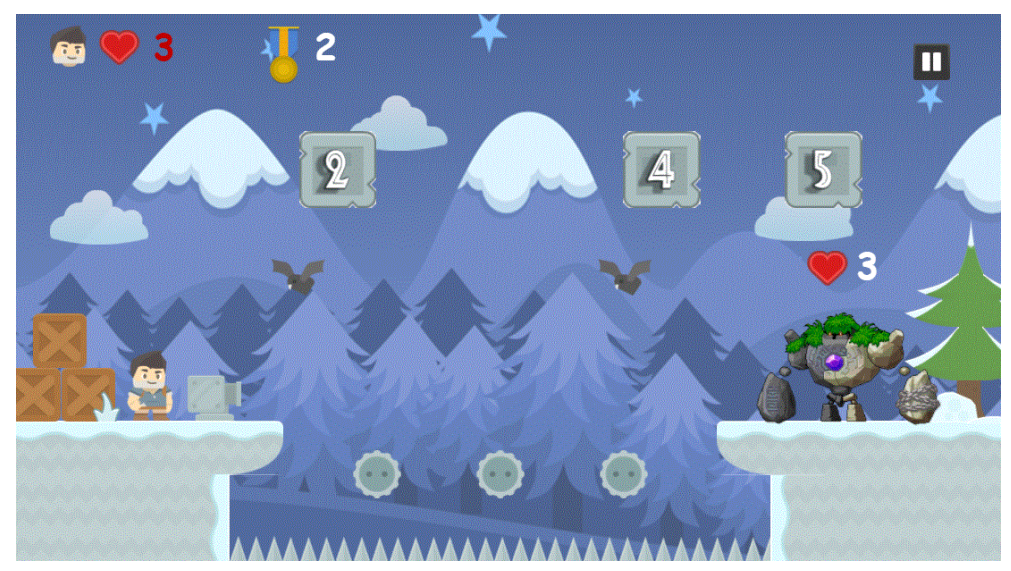

Gambar 7. Tampilan Boss Level pada Game STATIC

Media pembelajaran yang telah dikembangkan kemudian dinilai kualitasnya untuk memenuhi kriteria kevalidan. Kevalidan Game STATIC ditentukan berdasarkan penilaian para ahli media atau validator. Game STATIC yang sudah dinyatakan valid dan layak bisa digunakan dalam penelitian di lapangan. Tabel 2. merupakan hasil penilaian validasi Game STATIC dari para validator ahli media.

Tabel 2. Hasil Validasi Media Game STATIC oleh Ahli Media

\begin{tabular}{ccc}
\hline No. & Keterangan & Hasil \\
\hline 1 & Jumlah Butir & 35 \\
2 & Skor Maksimal & 175 \\
3 & Skor Minimal & 35 \\
4 & Skor Validator 1 & 151 \\
5 & Skor Validator 2 & 153 \\
\hline & Skor Rata-Rata & 152 \\
& Klasifikasi & Sangat Baik \\
\hline
\end{tabular}

Dapat dilihat pada Tabel 2. bahwa skor dari validator 1 sebesar 151 dan validator 2 sebesar 153, sehingga rata-rata yang diperoleh adalah 152 dengan klasifikasi sangat baik. Hasil ini menunjukkan bahwa game yang dikembangkan memenuhi kriteria valid dan layak digunakan sebagai media pembelajaran. Hasil penilaian oleh ahli media yang lebih rinci dapat dilihat pada Tabel 3. 
Mathematics and Educations Journal

Volume 1 Nomor 1, Juni 2019

Tabel 3. Rincian Hasil Validasi Media Game STATIC oleh Ahli Media

\begin{tabular}{lccc}
\hline \multicolumn{1}{c}{ Indikator } & Rerata V1 & Rerata V2 & Rerata Total $(\overline{\boldsymbol{x}})$ \\
\hline Kualitas Konten & 4,50 & 3,50 & 4,00 \\
Tujuan Pembelajaran & 3,67 & 5,00 & 4,33 \\
Prosedur dan Umpan Balik & 4,50 & 5,00 & 4,75 \\
Efisiensi & 4,67 & 3,33 & 4,00 \\
Desain Interface & 4,00 & 4,33 & 4,17 \\
Interaktivitas & 4,83 & 4,83 & 4,83 \\
Aksesbilitas & 5,00 & 4,00 & 4,50 \\
Usabilitas & 4,00 & 4,00 & 4,00 \\
Kesesuaian Standar & 4,00 & 4,00 & 4,00 \\
\hline
\end{tabular}

Media Game STATIC mengalami beberapa perbaikan atau revisi selama proses pengembangannya. Penilaian, komentar, dan saran para ahli dijadikan sebagai acuan untuk meningkatkan kualitas Game STATIC. Berdasarkan Tabel 3. diperoleh bahwa rerata total tertinggi berada pada indikator interaktivitas $(\overline{\boldsymbol{x}}=4,83)$. Interaktivitas yang baik merupakan salah satu hal penting dan menujukkan bahwa game dapat mudah digunakan oleh siswa [22].

Selain itu, berdasarkan Tabel 3. juga dapat dilihat bahwa rerata total indikator terendah berada pada kualitas konten, efisiensi, usabilitas, dan kesesuain standar $(\overline{\boldsymbol{x}}=4,00)$. Perlu dilakukan perbaikan agar skor indikator tersebut dapat meningkat dan kualitas produk menjadi lebih baik. Salah satu perbaikan yang dilakukan adalah merevisi tampilan sintaks perencanaan penyelidikan pada game. Sebelum revisi, sintaks tersebut menampilkan petunjuk game (bukan materi) bagi siswa. Setelah revisi, sintaks menampilkan informasi berupa materi pembelajaran yang dibutuhkan siswa untuk menjawab masalah awal. Selain itu, indikator kesesuaian standar juga perlu diperhatikan. Konteks yang disajikan dalam game harus sesuai dengan umur dan kemampuan siswa [23].

Kompetensi dan tujuan yang ingin dicapai merupakan salah satu aspek yang perlu diperhatikan dalam mengembangkan media pembelajaran game [24]. Melalui revisi yang dilakukan diharapkan Game STATIC dapat memenuhi tujuan utama dari 
Mathematics and Educations Journal

Volume 1 Nomor 1, Juni 2019

pengembangannya, yaitu agar siswa dapat memahami konsep statistika. Selain itu, belajar dengan Game STATIC juga untuk meningkatkan minat belajar matematika siswa. Sesuai dengan penelitian Pratama \& Setyaningrum, bahwa game pada pembelajaran matematika dapat memberikan efek positif pada pemahaman konsep dan minat belajar siswa [25].

\section{KESIMPULAN}

Produk yang dikembangkan berupa media pembelajaran matematika Game STATIC memenuhi kriteria valid setelah dinilai oleh para ahli. Beberapa indikator seperti kualitas konten, tujuan pembelajaran, prosedur dan umpan balik, efisiensi, desain interface, interaktivitas, aksesbilitas, usabilitas, dan kesesuaian standar dari Game STATIC dinyatakan valid. Adapun klasifikasi kevalidan media berada pada klasifikasi sangat baik, sehingga Game STATIC layak digunakan sebagai salah satu alternatif media pembelajaran di dalam kelas maupun luar kelas. Melalui Game STATIC minat belajar siswa dan pemahaman konsep khususnya pada materi statistika dapat meningkat. Penelitian lebih lanjut diperlukan untuk mengetahui keefektifan Game STATIC dari berbagai aspek kognitif maupun afektif lainnya.

\section{DAFTAR PUSTAKA}

[1] Sorathia, K. \& Servidio, R. (2010). Learning and experience: teaching tangible interaction \& edutainment. Procedia - Social and Behavioral Sciences 64, 265274. http://doi.org/10.1016/j.sbspro.2012.11.031

[2] Demirbilek, M. \& Tamer, S. L. (2010). Math teachers' perspectives on using educational computer games in math education. Procedia Social and Behavioral Sciences, 9, 709-716. http://doi.org/10.1016/j.sbspro.2010.12.222

[3] Daily Social. (2016). Retrieved from https://dailysocial.id/post/memahamitrenpenggunaan- smartphone-di-indonesia-berdasarkanusia/

[4] Wirawan, S., et al. (2013). Analysis of child computer interaction in edutainment and simulation games application on android platform in indonesia. (IJACSA) International Journal of Advanced Computer Science and Applications, 4(7), 174-178.

[5] Boyle, E. \& Connolly, T. (2008). A review of theories of player enjoyment in playing computer games, Proceedings of the 2nd European Conference on Games-Based Learning, Reading: Academic Publishing.

[6] Winarko, E. (2017). Pembelajaran matematika berbasis TIK untuk meningkatkan literasi matematika: peluang dan tantangan, Prosiding Seminar Nasional 
Matematika dan Pendidikan Matematika, Universitas Negeri Yogyakarta, Yogyakarta, Indonesia.

[7] Kebritchi, M., Hirumi, A., \& Bai, H. (2010). The effects of modern mathematics computer games on mathematics achievement and class motivation. Elsevier, $\begin{array}{llll}\text { Computers } \quad \& \quad \text { Education, } & \text { 427-443. }\end{array}$ https://doi.org/10.1016/j.compedu.2010.02.007

[8] Salsabila, N. H., \& Setyaningrum, W. (2018). Game "STATIC": Is It Interesting for Students? IOP Conf. Series: Journal of Physics: Conf. Series 1097 (2018) 012105. doi :10.1088/1742-6596/1097/1/012105

[9] Putra, W. D. P. \& Setyaningrum, W. The effect of edutainment toward students' interest in learning mathematics. IOP Conf. Series: Journal of Physics: Conf. Series 1097 (2018) 012120. doi:10.1088/1742-6596/1097/1/012120

[10] Sani, R. A. (2015). Pembelajaran Saintifik untuk Implementasi Kurikulum 2013. Jakarta, Indonesia: Bumi Aksara.

[11] Duch, B., J., Groh, S., E., \& Allen, D., E. (2001). The Power of Problem Based Learning. Streling, Virginia: Stylus.

[12] Kiilia, K., Moeller, K., \& Ninaus, M. (2018). Evaluating the eff ectiveness of a game-based rational number training - In-game metrics as learning indicators. $\begin{array}{lllll}\text { Computer } \& \quad \text { Education, } & 120,\end{array}$ https://doi.org/10.1016/j.compedu.2018.01.012

[13] Prince, U. K. (2017). Effect of mathematics game-based instructional techniques on students' achievements and interest in algebra, at basic education level. Department Of Science Education, Faculty of Education University Of Nigeria, NSUKKA Press.

[14] Ardani, R. A., Salsabila, N. H., Handican, R., \& Setyaningrum, W. (2018). The perceptions of students and teachers about the use of edutainment instructional media in mathematics learning. Advances in Social Science, Education and Humanities Research (ASSEHR), 160, 228-234.

[15] Branch, R. M. (2009). Instructional Design: The ADDIE Approach. New York, NY: Springer.

[16] Nieveen, N. (1999). Prototyping to Reach Product Quality. Design Approaches and Tools in Education and Training, Springer, 125-135.

[17] Allen, M. J. \& Yen, W. M. (1979). Introduction to Measurement Theory. Monterey, California: Brooks/Cole Publishing Company.

[18] Leacock, T. L., \& Nesbit, J. C. (2007). A Framework for evaluating the quality of multimedia learning resources. Educational Technology \& Society, 10 (2), 4459.

[19] Widoyoko, E. P. (2016). Evaluasi Program Pembelajaran. Yogyakarta, Indonesia: Pustaka Pelajar.

[20] Setyaningrum, W. \& Waryanto, N. H. (2017). Media edutainment segi empat berbasis android: apakah membuat belajar matematika lebih menarik? Jurnal Mercumatika: Jurnal Penelitian Matematika dan Pendidikan Matematika, 2(1). https://doi.org/10.26486/jm.v2i2.369.

[21] Abdullah, N. I., Tarmizi, R. A., \& Abu, R. (2010). The effects of problem based learning on mathematics performance and affective attributes in learning statistics at form four secondary level. Procedia Social and Behavioral 
Mathematics and Educations Journal

Volume 1 Nomor 1, Juni 2019

Sciences, 8, 370-376. http://doi.org/10.1016/j.sbspro.2010.12.052

[22] Ardani, R. A. \& Setyaningrum, W. Game-based edutainment media using guided discovery approach: what teachers say? IOP Conf. Series: Journal of Physics: Conf. Series 1097 (2018) 012101. doi:10.1088/1742-6596/1097/1/012101

[23] Setyaningrum, W. \& Waryanto, N. H. (2018). Developing mathematics edutainment media for Android based on students' understanding and interest: a teachers' review. IOP Conf. Series: Journal of Physics: Conf. Series 983. http://doi.org/10.1088/1742-6596/983/1/012093

[24] Charsky, D. (2010). From edutainment to serious games: a change in the use of game characteristics. Games and Culture, 5(2), 177-198. http://doi.org/10.1177/1555412009354727

[25] Pratama, L. D. \& Setyaningrum, W. Game-based learning: the effects on student cognitive and affective aspects. IOP Conf. Series: Journal of Physics: Conf. Series 1097 (2018) 012123. doi:10.1088/1742-6596/1097/1/012123 